\title{
ESTIMATION OF SHEAR STRENGTH PARAMETERS OF LATERITIC SOILS USING ARTIFICIAL NEURAL NETWORK
}

\author{
S. D Iyeke ${ }^{1, *}$, E. 0 Eze ${ }^{2}$, J. 0 Ehiorobo, ${ }^{3}$ and S. 0 Osuji ${ }^{4}$

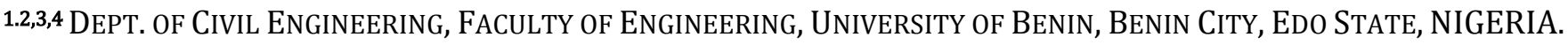 \\ E-mail addresses: ${ }^{1}$ solomon.iyeke@uniben.edu, ${ }^{2}$ eoeze@yahoo.com, ${ }^{3}$ jacehi@uniben.edu, ${ }^{4}$ osujisyl@yahoo.com
}

\begin{abstract}
This research work seeks to develop models for predicting the shear strength parameters (cohesion and angle of friction) of lateritic soils in central and southern areas of Delta State using artificial neural network modeling technique. The application of these models will help reduce cost and time in acquiring geotechnical data needed for both design and construction in the study area. A total of eighty-three (83) soil samples were collected from various locations in Delta State of Nigeria. The geotechnical soil properties were determined in accordance with British Standards. The range of the angle of internal friction and cohesion obtained from the tests are 2 to 43 degrees and 3 to $82 \mathrm{kN} / \mathrm{m}^{2}$ respectively. The optimum artificial neural network architecture network was found to be 3-9-1, that is three inputs, nine hidden layer nodes, and one output node for cohesion. While, the angle of friction had an optimal network geometry of 3-11-1, that is three inputs, eleven hidden layer nodes, and one output node. The results of the coefficient of determination and root mean square showed that the artificial neural network method outperforms some selected empirical formulae in the prediction of shear strength parameters.
\end{abstract}

\section{Keywords: Artificial Neural Network, Lateritic Soil, Angle of Friction, Cohesion}

\section{INTRODUCTION}

One of the most essential engineering properties of soil is its capacity to oppose sliding along inner surfaces within a mass. The solidity of any structure built on soil will depend upon the shearing resistance presented by the soil along likely surfaces of slippage [1]. The understanding of the shear strength of a soil is important in the assessment of bearing capacities of foundations [2], slope stability [3], retaining structures, embankment dams [4], tunnel linings, pavement [5] and the resistance traction and tillage tools in agricultural applications [6].The shear strength of soils is generally represented by the MohrCoulomb theory. The theory, indicate that the shear strength of soils varies linearly with the applied stress through two shear strength factors; cohesion and angle of shearing resistance $[7,8]$. The tangent to the Mohr-Coulomb failure envelopes is defined by its slope and intercept. The slope expressed in degrees is the angle of shearing resistance and the intercept is the cohesion $[9,10,11]$. The soil shear strength parameters can be determined either in the field or in the laboratory. The triaxial compression and direct shear tests are the most common tests for determining the cohesion and angle of friction values in the laboratory. Measurements of shear strength properties both at field and laboratory conditions are cumbersome, expensive, time-consuming and labourintensive $[7,8,12]$. In order to cope with the difficulty of experimental investigation, engineering design models are needed. Correlations and empirical relationships are principally useful in preliminary studies, or when due to time and/or financial constraints that a thorough geotechnical examination cannot to be conducted. This is most relevant in third world countries where up-to-date testing equipment are lacking together with the trained manpower needed to operate them. In the recent years, the development of prediction models that use easier to determine secondary information to spatially extend sparse and expensive soil measurements has been a sharpening focus of research [13]. Empirical correlations are widely used in geotechnical engineering practice as a tool to estimate the 
engineering properties of soils. Useful correlations exist between the index properties obtained from simple routine testing and the strength properties of soils among others [14].

Several empirical procedures have been developed over the years to estimate the shear strength parameters for soils. Among the various models developed are; Masada [15] for clay and silt embankments, Mofiz and Rahman [16] for Barind soils, Cola and Cortellazo [17] for peaty soils and Hajarwish and Shakor [18] for mudrock. Also, some models have been developed based on sustained hypothesis imposed by the researchers before estimation of the model parameters according to their assumptions concerning how the model parameters the dependent and explanatory variables are related, [7, 8, 18-21]. Hence these various models may not have been the appropriate ones. The advent of soft computing methods like artificial neural network(ANN) in developing robust models, where the data trend are allowed to evolve a appropriate models is becoming widely accepted. There are little or no documentation with regards to the use of these modeling tools for the prediction of shear strength parameters for lateritic soils. This research work seeks to develop a relationship between index soils properties and shear strength parameters for lateritic soils.

\section{MATERIALS AND METHODS}

\subsection{Sampling and Sampling Locations}

Soils samples were collected at random points from central and southern areas of Delta State. The sampling locations lie within longitude $5^{0} 30^{\prime} \mathrm{E}$ and $6^{0}$ $20^{\prime} \mathrm{E}$ and latitude $5^{0} 10^{\prime} \mathrm{N}$ and $6^{0} 20^{\prime} \mathrm{N}$. Delta State is one of the states in the Niger Delta Region, it has twenty-five local government areas. The location of Delta State and soil samples locations are shown in Figures 1 and 2 respectively. Disturbed soil samples were obtained at different depths $(1 \mathrm{~m}-25 \mathrm{~m})$ from road cuttings and borrow pits at various locations using hand auger. Also additional soil data were obtained from construction and consultancy firms. A total of eighty - three soil data were collected.

\subsection{Geotechnical Analysis of the Soils}

The classification tests as well as tests to determine the moisture-density relationship and shear strength were carried out in accordance to BS 1377 [22]. The shear tests were conducted in compliance to BS 1377 [22]. The geotechnical tests are; grain size distribution, plastic limit, liquid limit, specific gravity, compaction, shear box tests and triaxial compression tests.

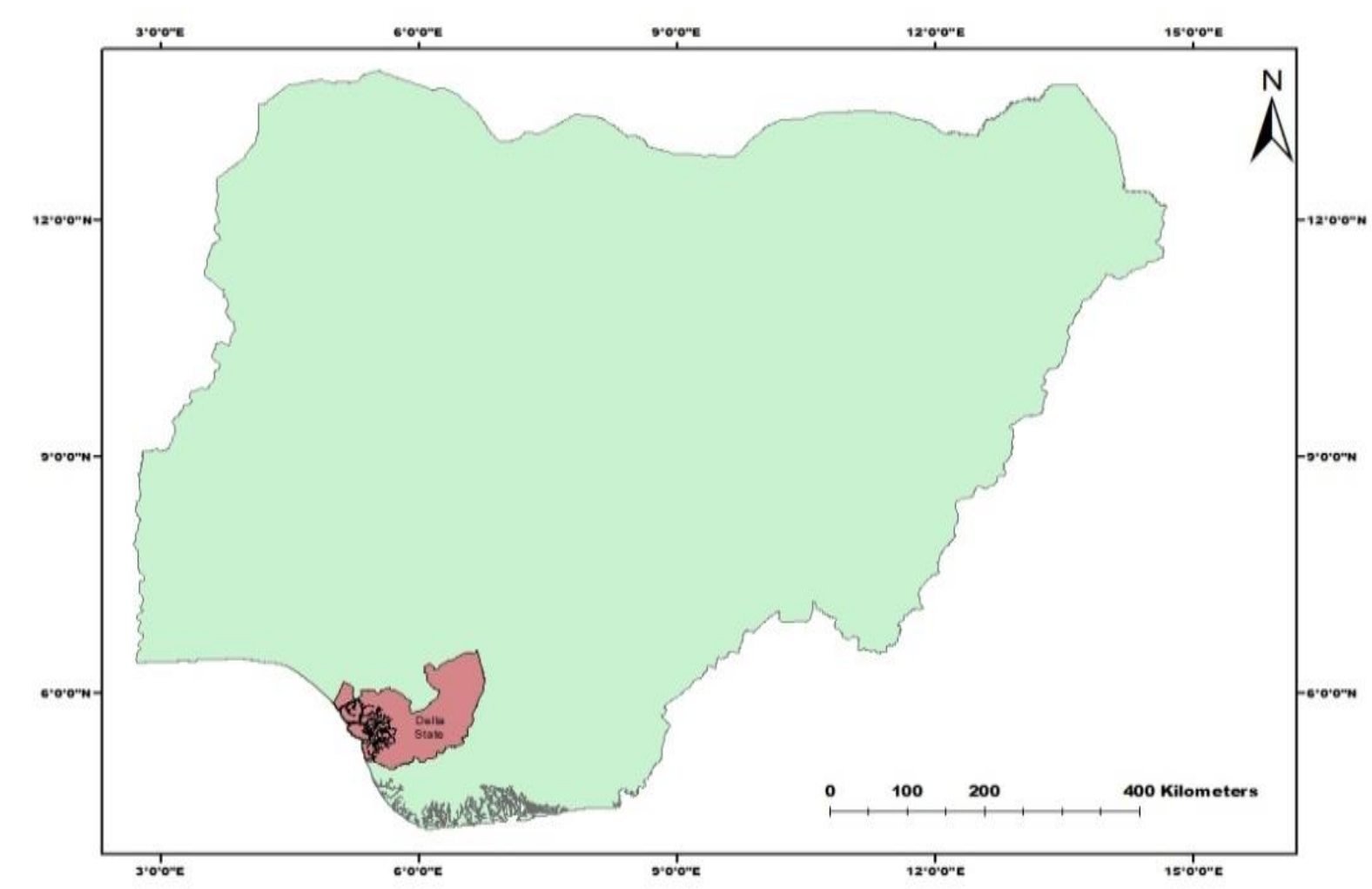

Figure 1. Map of Nigeria Showing Delta State 


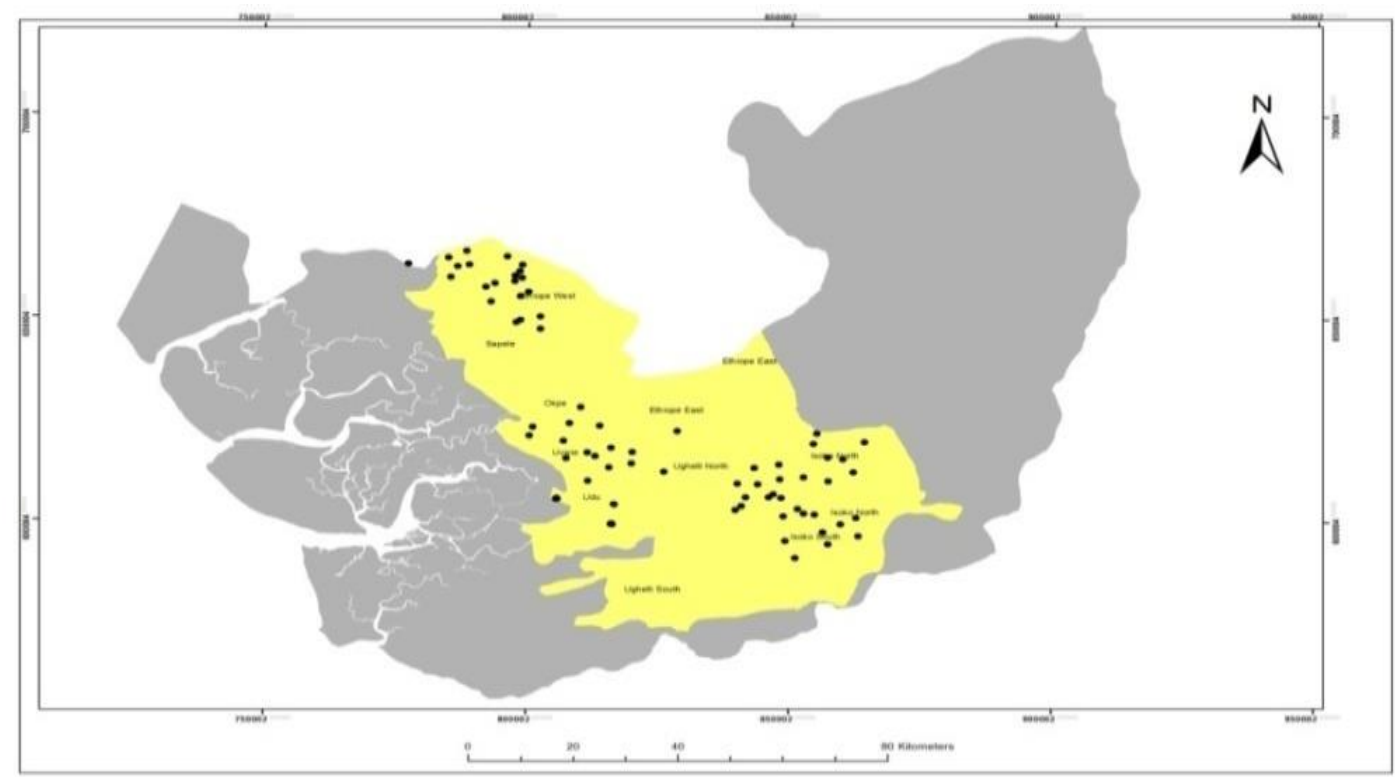

Figure 2. Map of Delta State Showing Samples Locations and Study Area

\subsection{ANN Modeling Procedure}

The input factors considered for shear strength parameters included; plasticity index, percentage of particles passing sieve No.200, specific gravity, liquid limit, plastic limit $[7,20,21,23,24]$. The inputs selected is based on the fact that soils classification is based on these parameters and the specific gravity is a reflection of the inert properties of the soil. Cohesion and angle of friction were the single output variables in the various models. Correlation matrix for input variables was determined using the Pearson correlation. Pearson correlation is one of the variable ranking criteria used in selecting inputs for ANN [25, 26].

The proposed multi-layer perception for the prediction of angle of internal friction and cohesion in the soil problem is shown in Figure 3.

The input to the multi-layer perceptron is a vector of $M$ attribute values

$$
x_{J}^{T}=\left[x_{1}, x_{2}, x_{3}, x_{4}, x_{5}\right]
$$

Where $j=1,2,3,4,5$ are the input variables.

The output of the weighting and summation in the first layer, the "hidden" layer, can be written as

$$
y_{j}^{(1)}=W^{(1) T} x_{j}
$$

Where $y_{j}^{(1)}=\left[\begin{array}{c}y_{1 j}^{(1)} \\ y_{2 j}^{(1)} \\ y_{3 j}^{(1)} \\ y_{4 j}^{(1)} \\ y_{5 j}^{(1)}\end{array}\right], x_{j}=\left[\begin{array}{c}1 \\ x_{1 j} \\ x_{2 j} \\ x_{3 j} \\ x_{4 j} \\ x_{5 j}\end{array}\right]$,

and

$$
W^{(1) T}=\left[\begin{array}{l}
w_{10}^{(1)} w_{20}^{(1)} w_{30}^{(1)} w_{40}^{(1)} w_{50}^{(1)} \\
w_{11}^{(1)} w_{21}^{(1)} w_{31}^{(1)} w_{41}^{(1)} w_{51}^{(1)} \\
w_{12}^{(1)} w_{22}^{(1)} w_{32}^{(1)} w_{42}^{(1)} w_{52}^{(1)} \\
w_{13}^{(1)} w_{23}^{(1)} w_{33}^{(1)} w_{43}^{(1)} w_{53}^{(1)}
\end{array}\right]
$$

The nonlinear function can be written as:

$$
z_{k j}^{(1)}=f\left(y_{k j}^{(1)}\right)
$$

The output of the second layer can then be written as

$$
z_{j}^{(2)}=f^{2}\left(y_{j}^{(1)}\right)
$$

The two-layer perceptron shown in Figure 3 can be also written in nested form as

$$
z_{j}^{(2)}=f^{(2)}\left(w^{(2) T} f^{(1)}\left(w^{(1) T} x_{j}\right)\right)
$$

There are no general guidelines in determining the number of data for training the artificial neural network model to perform effectively. However Lawrence and Fredeickson [27] suggested the following rule of thumb;

$$
2(i+h+o) \leq n \leq 10(i+h+o)
$$

Where: $i$ is the number of input neurons; $h$ is the number of hidden neuron; $o$ is the number of output neurons; $n$ is the number of data.

The database was randomly divided into three sets: training, testing, and validation. In total, $80 \%$ of the data were used for training and $20 \%$ were used for validation. The training data were further subdivided into $70 \%$ for the training set and $30 \%$ for the testing set [28].

The back propagation learning algorithm is the most popular and extensively used neural network algorithm [29-32]. 


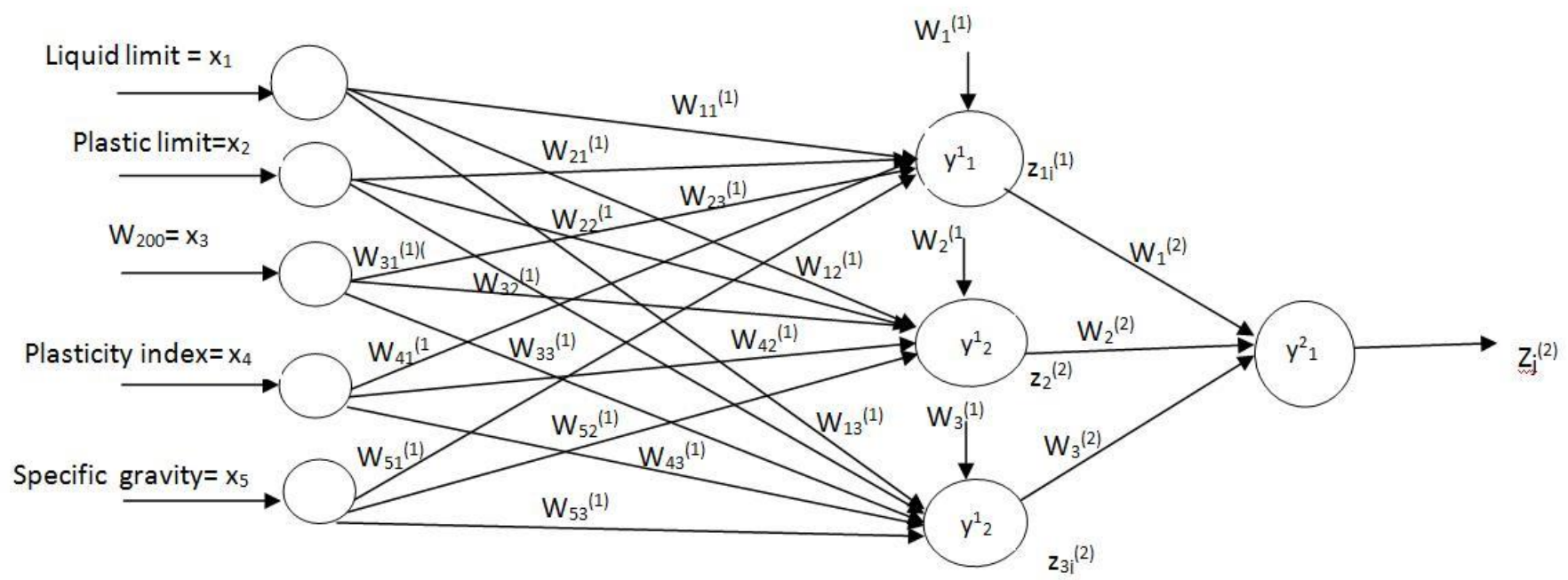

Figure3. Proposed Model structure Architecture

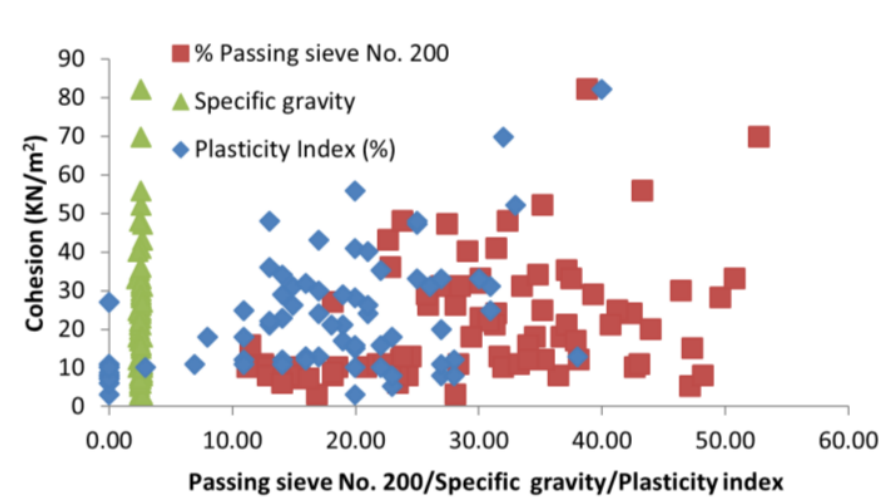

Figure 4. Scatter Plot of Cohesion and Other Soil Properties

The back-propagation neural network has been applied with great success to model many phenomena in the field of geotechnical and geo-environmental engineering [28, 33, 34]. Logarithmic sigmoid transfer function was used as the activation function for hidden and output layers. The input - output data of each ANN model were pre-processed to lie between 0 and 1 by using Eq. (8);

$$
X_{\text {norm }}=\frac{\left(X-X_{\min }\right)}{\left(X_{\max }-X_{\min }\right)}
$$

Where $X_{\text {norm }}$ is the normalized value, $X$ is the actual value, $X_{\max }$ is the maximum value and $X_{\min }$ is the minimum value.

The weights were first initialized to small arbitrary values. It is transmitted to obtain the solution using these initial weights. Once the output value has been calculated, we decrease the squared error, which can be written as a function of the weights as;

$$
E(w)=\frac{1}{2}\left(t_{j}-z_{j}^{(2)}\right)^{2}
$$

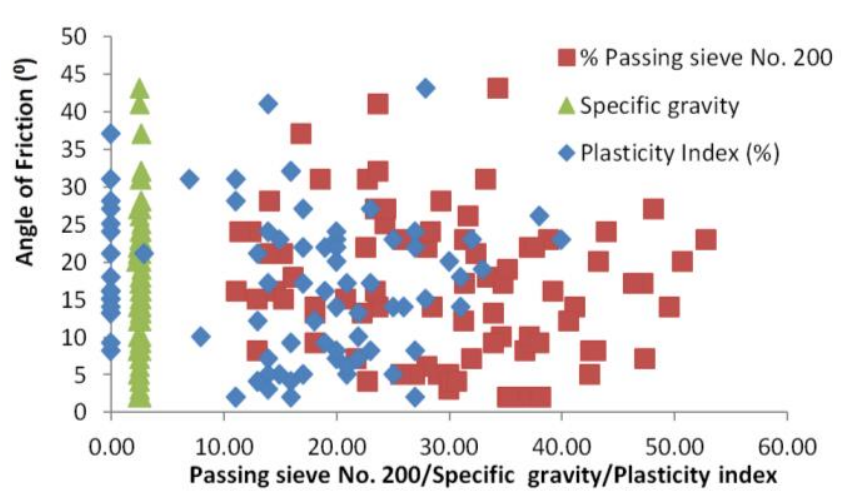

Figure5. Scatter Plot of Angle of Friction and Other Soil Properties

In equation (9) there is no superscript on the weights since we will use this equation to compute the values for both sets of weights. The difference in the weight values can be evaluated using the gradient descent method [35], in which we differentiate the error term with respect to the weights, giving

$$
w=-\eta \frac{\partial E(w)}{\partial w}
$$

where $\eta$ is a scaling value between 0 and 1 . The weights are updated iteratively by the equation $\mathrm{w}(\mathrm{u}+1)=w(u)+\Delta w(u)$ where $\mathrm{w}(\mathrm{u}+1)$ is the new weight; $w(u)$ is the old weight and $\Delta w(u)$ is the variation between the values of new and old weights.

Once the training phase of the model has been effectively completed, the presentation of the trained model is evaluated using the validation data, which have not been used as part of the model building process.. The coefficient of determination $\left(r^{2}\right)$, the root-mean-square error (RMSE), and the mean 
absolute error (MAE) [36], are the main criteria that are used to assess the performance of the ANN models obtained in this work.

$$
\begin{aligned}
& \text { Root mean square error }=\sqrt{\frac{\sum_{i=1}^{n}\left(x_{i}-y_{i}\right)^{2}}{n}} \\
& \text { Mean absolute error }=\frac{\sum_{i=1}^{n}\left|x_{i}-y_{i}\right|}{n} \\
& =\frac{\sum_{i=1}^{n}\left(X_{i}-\check{X}\right) *\left(Y_{i}-\check{Y}\right)}{\sqrt{\sum_{i=1}^{n}\left(X_{i}-\check{X}\right)^{2} *\left(Y_{i}-\check{Y}\right)^{2}}}
\end{aligned}
$$

\section{RESULTS AND DISCUSSIONS}

\subsection{Statistical Analysis of Data}

Statistical descriptions of examined soils parameters are given in Table 1 . It can be seen from the Table, that the distribution of the medium and average values of the soil properties are close together. This shows that soil experimental data are approximately normally distributed. This is further collaborated by the values of the skewness ( -0.925 to 1.529$)$ and kurtosis ( -0.673 to 2.873). These values are close to zero indicating slight skewness and asymmetry degree with reference to normal distribution.
The scatter diagrams plots for between cohesion and liquid limit, plasticity index, passing sieve No. 200 is shown in Figure 4, while that of angle of friction and liquid limit, plasticity index, passing sieve No. 200 is shown in Figure 5.

As can be seen from the Figures 4 and 5, there are extremely nonlinear relationships among the selected parameters, and several uphill and downhill points which exist on the graphs. In all the graphs, the points are not very useful at explaining the relationship with reference to the dependent variables. A correlation matrix was carried out on the soil parameters using the Pearson's correlation. The correlation matrix is given in Table 2. The matrix indicated a high correlation between liquid limit, plastic limit and plasticity index.

The liquid limit and plastic limit parameters were expunged from the models to avoid multicollinearity. Also the correlation of cohesion and angle of internal with the other soil parameters did not give a high relationship, hence using regression analysis is likely to produce inappropriate model. The soil data were divided into three sets; Training set, Testing set and Validation sets. The statistics for each set is given in Table 3

\begin{tabular}{|c|c|c|c|c|c|c|c|}
\hline Soil Parameters & $\begin{array}{c}\text { Liquid } \\
\text { Limit } \\
(\%)\end{array}$ & $\begin{array}{l}\text { Plasticity } \\
\text { Index (\%) }\end{array}$ & $\begin{array}{c}\text { Plastic } \\
\text { Limit } \\
(\%)\end{array}$ & $\begin{array}{l}\text { Specific } \\
\text { Gravity }\end{array}$ & $\begin{array}{c}\text { Passing } \\
\text { Sieve } \\
\text { No. } 200 \\
(\%)\end{array}$ & $\begin{array}{l}\text { Cohesion } \\
\left(\mathrm{KN} / \mathrm{m}^{2}\right)\end{array}$ & $\begin{array}{l}\text { Angle of } \\
\text { Internal } \\
\text { Friction } \\
\left({ }^{0}\right)\end{array}$ \\
\hline Liquid Limit (\%) & 1.0000 & & & & & & \\
\hline Plasticity Index (\%) & 0.9120 & 1.0000 & & & & & \\
\hline Plastic Limit (\%) & 0.6626 & 0.6807 & 1.0000 & & & & \\
\hline Specific Gravity & -0.2970 & -0.3866 & -0.1695 & 1.0000 & & & \\
\hline Passing Sieve No. 200 (\%) & 0.6197 & 0.6647 & 0.6074 & -0.5002 & 1.0000 & & \\
\hline Cohesion $\left(\mathrm{KN} / \mathrm{m}^{3}\right)$ & 0.4898 & 0.5291 & 0.3689 & -0.0346 & 0.3841 & 1.0000 & \\
\hline Angle of Internal Friction $\left({ }^{0}\right)$ & 0.0044 & -0.0466 & -0.0929 & 0.2627 & -0.1756 & -0.0935 & 1.0000 \\
\hline
\end{tabular}

Table 1. Basic Descriptive Statistics for the soil Data

\begin{tabular}{lcccccc}
\hline Statistics & $\begin{array}{c}\text { Passing Sieve } \\
\text { No.200 }(\%)\end{array}$ & $\begin{array}{c}\text { Plasticity } \\
\text { Index }(\%)\end{array}$ & $\begin{array}{c}\text { Liquid Limit } \\
(\%)\end{array}$ & $\begin{array}{c}\text { Specific } \\
\text { Gravity }\end{array}$ & $\begin{array}{c}\text { Cohesion } \\
\left(\mathrm{kN} / \mathrm{m}^{2}\right)\end{array}$ & $\begin{array}{c}\text { Angle of } \\
\text { Friction }\left({ }^{0}\right)\end{array}$ \\
\hline Minimum & 11.20 & 0.0 & 12 & 2.2 & 3 & 2 \\
Maximum & 52.80 & 40.0 & 55 & 2.69 & 82 & 43 \\
Average & 29.86 & 15.5 & 31.25 & 2.54 & 21.24 & 16.71 \\
Medium & 30.1 & 16.0 & 31 & 2.56 & 16.0 & 16 \\
Standard deviation & 10.36 & 10.4 & 8.741 & 0.10 & 15.27 & 9.52 \\
Skewness & 0.108 & -0.085 & 0.310 & -0.956 & 1.529 & 0.425 \\
Kurtosis & -0.672 & -0.673 & -0.162 & 0.841 & 2.873 & -0.231 \\
$\mathrm{n}$ & 83 & 83 & 83 & 83 & 83 & 83 \\
\hline
\end{tabular}

Table 2.Correlation Matrix of Soil Parameters with Shear Strength Parameters. 
Table 3. Artificial Neural Network Input and Output Statistics

\begin{tabular}{|c|c|c|c|c|c|}
\hline \multirow[b]{2}{*}{ Model variables and data sets } & \multicolumn{5}{|c|}{ Statistical Parameters } \\
\hline & Mean & $\begin{array}{c}\text { Standard } \\
\text { Deviation }\end{array}$ & Minimum & Maximum & Range \\
\hline \multicolumn{6}{|l|}{ Plasticity Index (\%) } \\
\hline \multirow{3}{*}{$\begin{array}{l}\text { Training Set } \\
\text { Testing Set } \\
\text { Validation Set }\end{array}$} & 16.0 & 10.7 & 0.0 & 38.0 & 38.0 \\
\hline & 13.5 & 11.0 & 0.0 & 32.0 & 32.0 \\
\hline & 16.8 & 9.2 & 0.0 & 40.0 & 40.0 \\
\hline \multicolumn{6}{|l|}{ Specific Gravity } \\
\hline \multirow{3}{*}{$\begin{array}{l}\text { Training Set } \\
\text { Testing Set } \\
\text { Validation Set }\end{array}$} & 2.5 & 0.1 & 2.2 & 2.7 & 0.5 \\
\hline & 2.6 & 0.1 & 2.5 & 2.7 & 0.2 \\
\hline & 2.6 & 0.1 & 2.4 & 2.6 & 0.2 \\
\hline \multicolumn{6}{|l|}{ Passing Sieve No.200 (\%) } \\
\hline \multirow{3}{*}{$\begin{array}{l}\text { Training Set } \\
\text { Testing Set } \\
\text { Validation Set }\end{array}$} & 30.0 & 10.9 & 11.2 & 50.8 & 39.6 \\
\hline & 28.9 & 11.5 & 12.5 & 52.8 & 40.3 \\
\hline & 30.6 & 7.1 & 16.9 & 43.3 & 26.4 \\
\hline \multicolumn{6}{|l|}{ Cohesion $\left(\mathrm{KN} / \mathrm{m}^{2}\right)$} \\
\hline \multirow{3}{*}{$\begin{array}{l}\text { Training Set } \\
\text { Testing Set } \\
\text { Validation Set }\end{array}$} & 20.0 & 12.1 & 6.0 & 52.0 & 46.0 \\
\hline & 20.0 & 15.8 & 5.0 & 70.0 & 65.0 \\
\hline & 26.1 & 21.4 & 3.0 & 82.0 & 79.0 \\
\hline \multicolumn{6}{|l|}{ Angle of Friction $(0)$} \\
\hline \multirow{3}{*}{$\begin{array}{l}\text { Training Set } \\
\text { Testing Set } \\
\text { Validation Set }\end{array}$} & 14.7 & 8.5 & 2 & 31 & 29 \\
\hline & 19.6 & 9.6 & 5 & 41 & 36 \\
\hline & 18.6 & 11.1 & 2 & 43.0 & 41 \\
\hline
\end{tabular}

Despite trying numerous random combinations of training, testing, and validation sets, there are still some slight inconsistencies in the statistical parameters for the training, testing, and validation sets that are most closely matched. This can be attributed to the fact that the data contain singular, rare events, that cannot be replicated in all three data sets. However, on the whole, the statistics are in good agreement and all three data sets may be considered to represent the same population.

\subsection{Visual Basic Programme for ANN}

A program was written and run in Visual Basic for the proposed ANN model. The interface for the programme is shown in Figure 6. The multilayer perception (MLP) can have more than one hidden layer; however, several works have shown that a single hidden layer is sufficient for an ANN to approximate any complex nonlinear function [36, 37]. Therefore, in this study, a one-hidden-layer MLP was used. Logarithmic sigmoid transfer function was used as the activation function for hidden and output layers. The numbers of hidden layer neurons were found using simple trial-and-error method adjudged by the root mean square errors (RMSE).

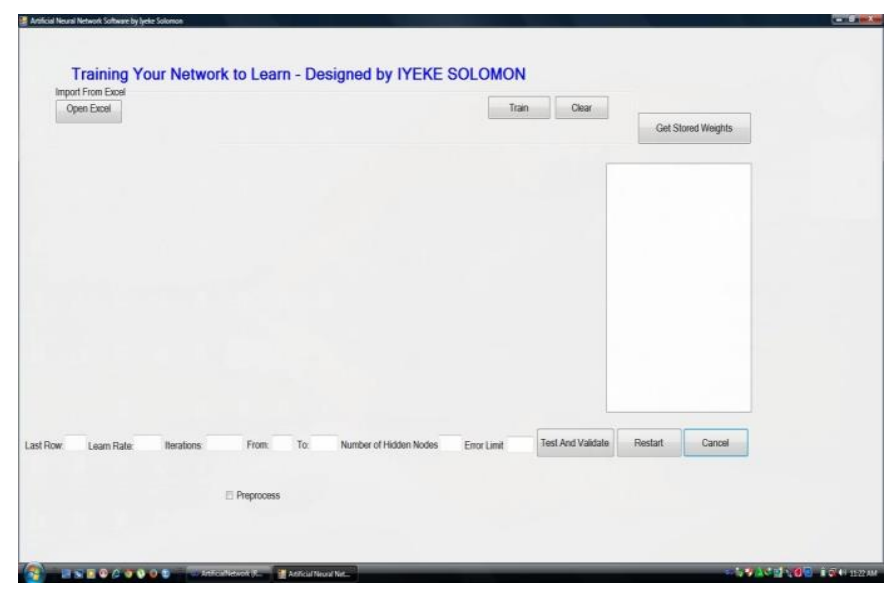

Figure 6. Visual Basic Interface Showing the Processing Functions

The optimal network architecture obtained for the cohesion model was 3-9-1 i.e., three inputs, nine hidden layer nodes, and one output node, the optimum learning rate was found to be 0.2 and results of the prediction is shown in Figures 7,8 and 9. Also, the optimal network architecture obtained for the angle of friction model was 3-11-1 i.e., three inputs, eleven hidden layer nodes, and one output node, the optimum learning rate was found to be 0.4 and the results of the prediction is shown in Figures 9,10 and 11 . 


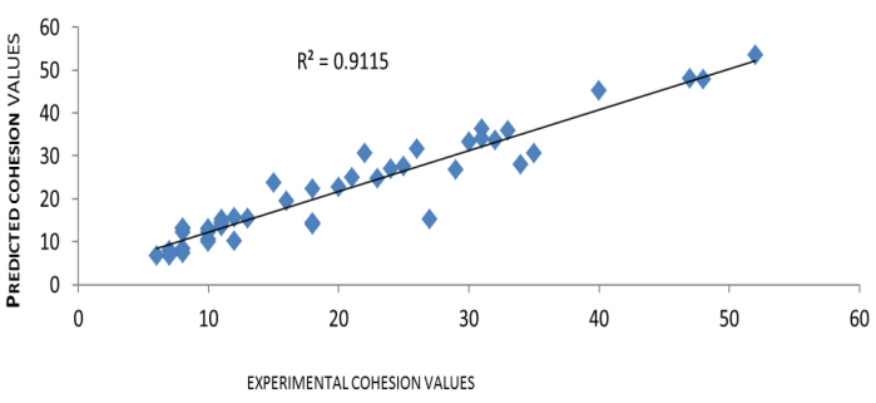

Figure 7(a).Predicted cohesion values versus Experimental Cohesion Values for Training Set

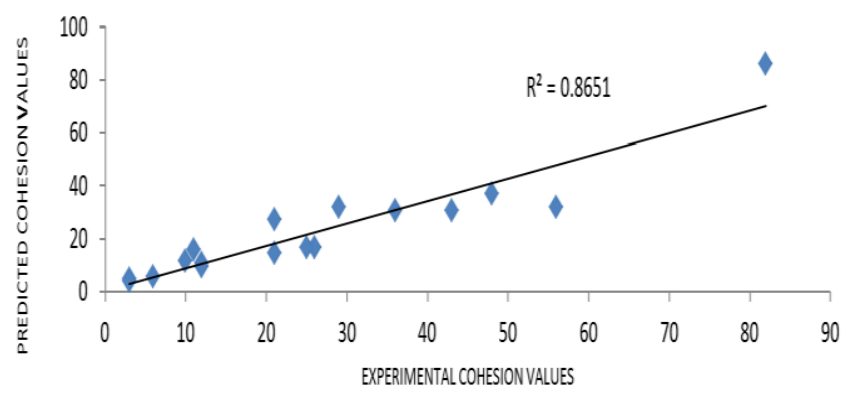

Figure 8. Predicted cohesion values versus Experimental Cohesion Values for Validation Set

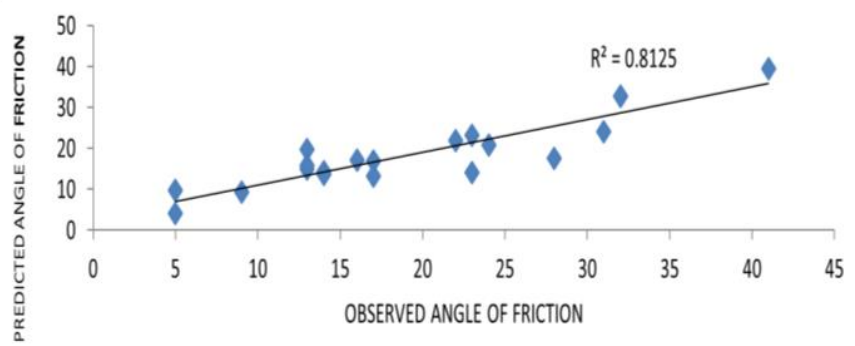

Figure 10. Predicted Angle of Friction values versus Experimental Angle of Friction Values for Testing Set

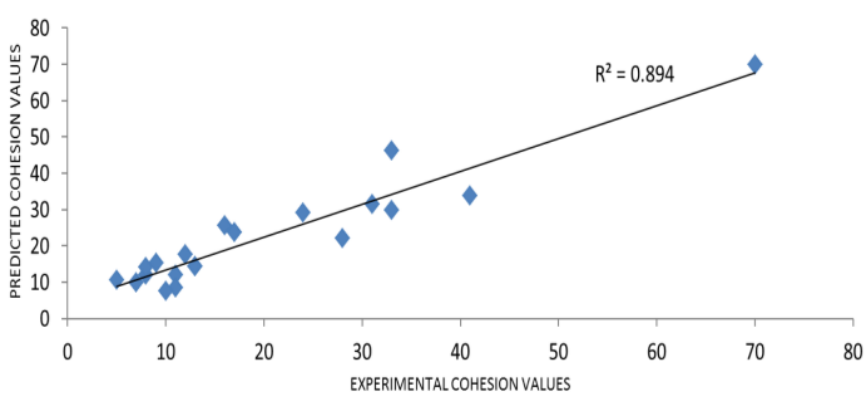

Figure 7(b). Predicted cohesion values versus Experimental Cohesion Values for Testing Set

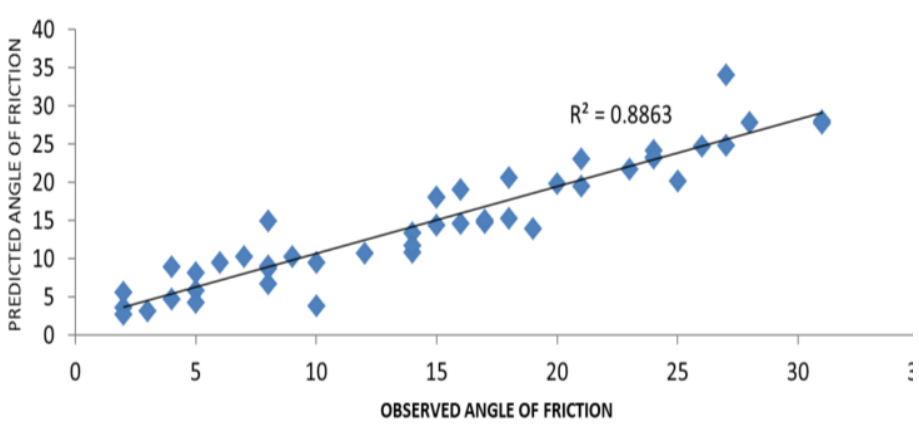

Figure 9. Predicted Angle of Friction values versus Experimental Angle of Friction Values for Training Set

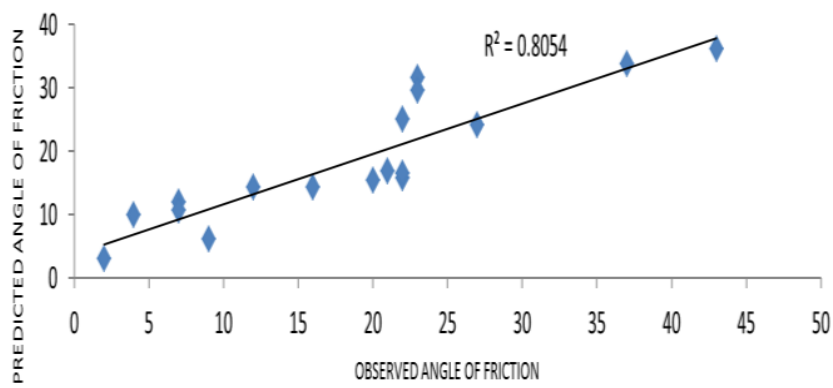

Figure 11.Predicted Angle of Friction values versus Experimental Angle of Friction Values for Validation Set.

Table 4. Comparison of Artificial Neural Network and Other Empirical Method for Cohesion Prediction

\begin{tabular}{|c|c|c|c|c|c|}
\hline $\mathrm{S} / \mathrm{N}$ & Factors Considered & ANN & Ersoy et al.([8] & Roy and Dass([7] & Adunoye[20] \\
\hline \multirow{4}{*}{1} & \multirow{4}{*}{ Cohesion equation } & \multirow{4}{*}{-} & & \multirow{4}{*}{$\begin{array}{l}-0.525+0.241^{*} \text { specific } \\
\text { gravity }\end{array}$} & (a) $0.685^{\star}$ fines +2.2 \\
\hline & & & - & & (b) $5.287 \mathrm{e}^{0.028^{\star} \text { fines }}$ \\
\hline & & & 204.5(PI/LL)+56.3(PI/LL)+31 & & (c ) $27.21 \ln$ (fines)-65.28 \\
\hline & & & & & $\begin{array}{l}\text { (d) }-0.004 \text { (fines) })^{2}+1.118 \text { (fines) } \\
-7.383\end{array}$ \\
\hline \multirow{4}{*}{2} & \multirow{4}{*}{$\begin{array}{l}\text { Coefficient of Correlation } \\
\left(R^{2}\right)\end{array}$} & \multirow{4}{*}{0.861} & \multirow{4}{*}{0.14} & \multirow{4}{*}{0.04} & (a) 0.219 \\
\hline & & & & & (b) 0.242 \\
\hline & & & & & (c) 0.19 \\
\hline & & & & & (d) 0.21 \\
\hline \multirow{4}{*}{3} & \multirow{4}{*}{$\begin{array}{l}\text { Root Mean Square Error } \\
\text { (RMSE) }\end{array}$} & \multirow{4}{*}{8.33} & \multirow{4}{*}{81.51} & \multirow{4}{*}{33.31} & (a) 19.16 \\
\hline & & & & & (b) 23.77 \\
\hline & & & & & (c) 18.77 \\
\hline & & & & & (d) 18.97 \\
\hline \multirow{4}{*}{4} & \multirow{4}{*}{$\begin{array}{l}\text { Mean Absolute Error } \\
\text { (MAE) }\end{array}$} & \multirow{4}{*}{6.08} & \multirow{4}{*}{75.54} & \multirow{4}{*}{26.45} & (a) 14.74 \\
\hline & & & & & (b) 16.34 \\
\hline & & & & & (c) 15.82 \\
\hline & & & & & (d) 14.60 \\
\hline
\end{tabular}


Table 5. Comparison of Artificial Neural Network and Other Empirical Method for Angle of Friction Prediction

\begin{tabular}{|c|c|c|c|c|c|}
\hline $\mathrm{S} / \mathrm{N}$ & $\begin{array}{l}\text { Factors } \\
\text { Considered }\end{array}$ & ANN & Ersoy et al.[8] & Roy and Dass [7] & Adunoye[21] \\
\hline
\end{tabular}

(a) $0.404 *$ fines +38.06

$1 \quad \begin{array}{ll}\text { Angle of } \\ \text { Friction }\end{array}$

equation

$-204.5(\mathrm{PI} / \mathrm{LL})+56.3(\mathrm{PI} / \mathrm{LL})+31$

$-29.604+34.220 *$ density

(b) -16.3 In

(fines) +78.07

(c) 0.001 (fines) $)^{2}$

0.571 (fines) +41.4

\begin{tabular}{|c|c|c|c|c|c|}
\hline 2 & $\begin{array}{l}\text { Coefficient of } \\
\text { Correlation } \\
\left(\mathrm{R}^{2}\right)\end{array}$ & 0.805 & 0.011 & 0.034 & $\begin{array}{l}\text { (a) } 0.0098 \\
\text { (b) } 0.0191 \\
\text { (c) } 0.0092\end{array}$ \\
\hline 3 & $\begin{array}{l}\text { Root Mean } \\
\text { Square Error } \\
\text { (RMSE) }\end{array}$ & 4.77 & 21.50 & 19.35 & $\begin{array}{l}\text { (a) } 33.76 \\
\text { (b) } 11.71 \\
\text { (c) } 451.22 \\
\end{array}$ \\
\hline 4 & $\begin{array}{l}\text { Mean } \\
\text { Absolute } \\
\text { Error (MAE) }\end{array}$ & 4.34 & 18.62 & 16.55 & $\begin{array}{l}\text { (a) } 31.76 \\
\text { (b) } 8.73 \\
\text { (c) } 451.08\end{array}$ \\
\hline
\end{tabular}

Many empirical methods for shear strength parameters prediction of soils are presented in literature. Among these, three have been chosen for the purpose of assessing the relative performance of the ANN model. These include the methods proposed by Ersoy et al. [8], Roy and Dass [7] and Adunoye $[20,21]$. These methods are chosen as the database used in this work contains most parameters required to calculate shear strength parameters by these methods. The performance of the empirical methods and the ANN model for the validation set are given in Tables 4 and 5 for cohesion and angle of friction respectively

\section{CONCLUSIONS}

A total of 83 set of soil data were obtained for the study area. The soil test data obtained were scattered over central and southern areas of Delta State. Generally, the ranges of the angle of internal friction and cohesion used were $2^{\circ}-43^{\circ}$ and $3 \mathrm{kN} / \mathrm{m}^{2}--82$ $\mathrm{kN} / \mathrm{m}^{2}$, respectively. The multilayer feed forward network was used to demonstrate the feasibility of ANNs to predict the shear strength parameters for lateritic soils in some areas of Delta State. A Pearson correlation analysis was carried out to study the relative relationship of the factors that affect shear strength parameters. The correlation analysis indicated a high level of relationship between plastic limit, liquid limit and plasticity index. Hence only the plasticity index was used in the modelling exercise. The optimum architecture for the ANN network for cohesion was found to be 3-9-1 i.e., three inputs, nine hidden layer nodes, and one output node with a learning rate of 0.2 . While the angle of friction had an optimal ANN geometry of 3-11-1 i.e., three inputs, eleven hidden layer nodes and a learning rate of 0.4 . The results between the predicted and measured shear strength parameters obtained by utilizing ANNs were compared with three traditional methods. The results obtained demonstrated that the ANN method outperforms the empirical methods considered.

\section{REFERENCES}

[1] Jain, R., Jain, P. K. and Bhadauria, S. S.,. Computational approach to predict, soil shear strength. International Journal of Engineering Science and Technology, 2(8), 2010, pp. 3874-3885.

[2] Too, V. K., 3D Modelling for geotechnical investigation, M.S. Thesis, Department of Environmental and Biosystems Engineering, School of Engineering, 2012, University of Nairobi.

[3] Liu R., Yun S. and Zhang, L.,. Vane shear strength based stability analysis of slopes in unconsolidated soft clay. Transactions of Tianjin University, Vol. 10, No. 3, 2004, pp.195-200.

[4] Ajdari, M., Habibagahi,G., Nowamooz, H.,Masrouri, F., and Ghahramani, A.,. Shear strength behavior and soil water retention curve of a dual porosity siltbentonite mixture. Transaction A: Civil Engineering, Sharif University of Technology. Vol. 17, No. 6, 2010, pp. 430-440.

[5] Tekinsoy, M.A., Kayadelen, C., Keskin , M.S., and Soylemez, A.,. An equation for predicting shear strength envelope with respect to matric suction. Computers and Geotechnics 31: 2004, pp. 589-593. 
[6] Fredlund, D.G. and Vanapalli, S.K.,. Shear strength of unsaturated soils. Agronomy Soil Testing Manual, Agronomy Society of America, 2002, pp. 329-361.

[7] Roy, S. and Dass, G.,. Statistical models for the prediction of shear strength parameters at Sirsa, India. International Journal Of Civil and Structural Engineering, Vol. 4, No. 4, 2014, pp. 483-498

[8] Ersoyl, H., Karsli, M. B., Cellek, S., Kul, B., Baykan, I., and Parsons, R.,. Estimation of the soil strength parameters in tertiary volcanic regolith (NE Turkey) using analytical hierarchy process. J. Earth Syst. Sci. 122, No. 6, 2013, pp. 1545-1555.

[9] Murthy, V. N. S., Geotechnical Engineering: Principles and Practices of Soil Mechanics, 2nd edn, Taylor and Francis, 2008, CRC Press, UK.

[10] Alsaleh, M. I., Numerical modeling for strain localization in granular materials using cosserat theory enhanced with microfabric properties. Ph.D. Thesis, Dept. of Civil and Environmental Engineering, Louisiana State University, 2004.

[11] Mollahasani, A., Alavi, A. H., Gandomi, A. H. and Rashed, A., , Nonlinear neural-based modeling of soil cohesion intercept, KSCE Journal of Civil Engineering, 15(5), 2011, pp 831-840.

[12] Arvidsson J. and Keller, T.,. Comparing penetrometer and shear vane measurements with measured and predicted moldboard plow draft in a range of Swedish soils. Soil and Tillage Research, 2011, 111:219-223.

[13] Bishop, T. F. A. and McBratney, A.B., A comparison of prediction methods for the creation of field-extent soil property maps.Geoderma, 103: 2001, pp. 149160.

[14] Sorensen, K. K. and Okkels, N., , Correlation between drained shear strength and plasticity index of undisturbed over consolidated clays. Proceedings of the $18^{\text {th }}$ International Conference on Soil Mechanics and Geotechnical Engineering, Paris, 2013, pp. 1-6.

[15] Masada, T.,. Shear Strength of Clay and Silt Embankments. Ohio Research Institute for Transportation and the Environment. Ohio University, Ohio, 2009.

[16] Mofiz, S.A. and Rahman M. M.. Shear strength behavior of barind soil on triaxial extension stress path tests.: 11th IAEG Congress, Auckland, New Zealand 2010, pp 2249-2256.

[17] Cola, S. and Cortellazzo, G., The shear strength behavior of two peaty soils. Geotechnical and Geological Engineering, 2005, 23:679-695.

[18] Hajdarwish, A. and Shakoor, A.. Predicting the shear strength parameters of mudrocks. The Geological Society of London. 2006, IAEG Paper number 607.
[19] Bravo, E, L.,Suarez, M. H.,Cueto, O. G., Tijskens, E. and Ramon, H.,. Determination of basics mechanical properties in a tropical clay soil as a function of dry bulk density and moisture. Revista Ciencias Técnicas Agropecuarias, Vol. 21, No. 3: 2012, pp 5-11.

[20] Adunoye, G. O.,. Study of relationship between fines content and cohesion of soil.British Journal of Applied Science and Technology 4(4), 2014: 682692.

[21] Adunoye, G. O.,. Fines content and angle of internal friction of a lateritic soil: An experimental study. American Journal of Engineering Research. 3(3), 2014, pp-16-21.

[22] B. S. 1377. Method of Testing for Civil Engineering Purpose. British Standard Institution, London, 1990, England.

[23] Goktepe, B., A., SelimAltun, GokhanAltintas and Ozcan Tan, Shear strength estimation of plastic clays with statistical and neural approaches. Journal of Building and Environment, Vol. 43,(5), 2008, pp. 849-860.

[24] Khanlari, G. R., Heidari, M., Momeni, A. A. and Abdilor, Y. Prediction of shear strength parameters of soils using artificial neural networks and multivariate regression methods. Engineering Geology, 131-132, 2012, pp.11-18.

[25] Guyon, I. and Elisseeff, A., An Introduction to variable and feature selection. Journal of Machine learning research, 3, 2003, 1157-1182.

[26] Wilby, R. L., Abrahart, R. and Dawson, C. W.. Detection of conceptual model rainfall-runoff processes inside an artificial neural network. Hydrological Sciences, 48 (2), 2003, 163-181.

[27] Lawrence, J. and Fredrickson, J. BrainMaker User's Guide and Reference Manual, 7th Ed., Nevada City, CA: California Scientific Software. 1998.

[28] Shahin, M. A., Jaksa, M. B. and Maier, H. R., .Predicting the settlement of shallow foundations on cohesionless soils using back-propagation neural networks. Journal of Geotechnical and Geoenvironmental Engineering, Vol. 128, No. 9, 2002, pp.785-793.

[29] Haque, M. E. and Sudhakar, K. V.. ANN backpropagation prediction model for fracture toughness in microalloy steel. International Journal of Fatigue, 24, 2002, 1003-1010.

[30] Kim, H., Rauch, A. F. and Haas, C. T. Automated quality assessment of stone aggregates based on laser imaging and a neural network. Journal of Computing in Civil Engineering 18 (1), 2004, 58-64.

[31] Singh, T. N., Gupta, A.R. and Sain, R. A comparative analysis of cognitive systems for the prediction of drill ability of rocks and wear factor, Geotechnical and Geological Engineering 242006 299-312. 
[32] Das, S.K. and Basudhar, P.K., Prediction of coefficient of lateral earth pressure using artificial neural networks, Electronic Journal of Geotechnical Engineering,10-Bundle 2005, A, paper 0506.

[33] Shahin, M. A., Jaksa, M. B. and Maier, H. R.,. Artificial neural network applications in geotechnical engineering, Australian Geomechanics 36 (1), 2001, 49-62.

[34] Amegashie, F., Shang, J. Q., Yanful, E. K., Ding, W. and Al-Martini, S.,. Using complex permittivity and artificial neural networks to identify and classify copper, zinc, and lead contamination in soil, Canadian Geotechnical Journal 43, 2006, 100-109.

[35] Rusell, B. H.,. The application of multivariate statistics and neural networks to the prediction of reservoir parameters using seismic attributes. PhD Thesis, Department of Geology and Geophysics, Calgary, Alberta.

[36] Erzin, Y., Hanumantha Rao, B., Patel, A., Gumaste, S.D. and Singh, D.N.,. Artificial neural network models for predicting electrical resistivity of soils from their thermal resistivity. International Journal of Thermal Sciences , 49, 2010, 118-130.

[37] Gunaydin, O., Gokoglu, A. and Fener, M.,. Prediction of artificial soil's unconfined compression strength test using statistical analyses and artificial neural networks. Advances in Engineering Software 41, 2010, 1115-1123. 